\title{
Research on Customer Value Measurement
}

\author{
Putengxin Liu
}

\author{
University of Maryland, College Park. College park, Maryland, United States, 20740 \\ ${ }^{*}$ Corresponding author. Email: lptx888@gmail.com
}

\begin{abstract}
The customer value proposition consists of the sum of benefits that a vendor promises a customer will receive in return for the customer's associated payment. This research paper aims to analyze a study about customer value measurement for different enterprises. This article illustrates how SMEs considered the costumer value differently. However, there are more analysis to extend this analysis based on some update business environment.
\end{abstract}

Keywords: Customer value, measurement, small and big enterprises

\section{INTRODUCTION}

Customer value somehow is very hard to measure due to the fact that there is not a universal standard for the value that a customer may provide for the company. The customer value should be express in monetary terms, then by the net benefits bring to the company. Value is also what customer gets in exchange for the price it pays [3]. Customer value is important for companies that People purchase a product or service only when they perceive that they will benefit from the transaction. Thus, it is essential to understand what companies' customers value most. Usually, this extends beyond core product features, functionality, and price point. [8]. Thus, this research paper will analysis how companies making different selections of measuring customer values. A further analysis of a research paper about Weibo of Tencent company will be included in this paper. It is important to connect some new studies to compare the differences or similarity of the customers valuation for both small and big enterprise and also for online and reality business.

\section{ANALYSIS OF SMES VALUATION TOWARDS COSTUMER'S VALUE MEASUREMENT}

Martin seeks to find out the customer value measurement methods and connect those methods to small or mid-size companies. In this article, he consider customer relationship management as the key to understanding costumers, feedback and long-term relationship with the companies and pinpoints out some possible difficulties for defining the customer value measurement, thus he points out some common approaches: 1. A lot of entrepreneurs measure customer satisfaction, but only a few entrepreneurs measure the profitability by individual customers. 2. A lot of companies quantify the individual customer value. Marketers can measure the customers' profitability not only according to the individual customers, but also according to the segments or distribution channels. These criteria allow to identify key customers. 3. Customer lifetime value. Customer lifetime value (CLTV) describes the net present value of the future earnings expected from all purchases throughout customer life. Estimated earnings are deducted from expected cost to attract, acquire, and serve the customer

Then, Martin aims to present the research results of customers, value measurement and to use in companies' marketing management through CRM databases.

The methodology authors states in his group fist gather data from a questionnaire distributed in the Moravian-Silesian region, then inserted data into an SPSS matrix to use the SPSS program for statistical calculations. The respondents were randomly selected, and the sample size was determined by the following formula:

$$
\begin{aligned}
& n=\frac{\left(\mathrm{z}^{2} \cdot \mathrm{p} \cdot \mathrm{q}\right)}{\mathrm{e}^{2}} \\
& n=\frac{\left(\left(1,962^{2} \cdot(0,05) \cdot(1-0,05)\right)\right.}{0,052^{2}} \quad n=384,16
\end{aligned}
$$


Table 1 The structure of the respondents' sample by enterprise size[1]

\begin{tabular}{|l|l|l|}
\hline Enterprise & Frequency & Percent \\
\hline Microenterprise & 301 & 40.9 \\
\hline Small & 230 & 31.3 \\
\hline Medium & 201 & 27.9 \\
\hline$\Sigma$ & 736 & 100 \\
\hline
\end{tabular}

Based on this division of those companies, it is clear to see that Martin divided enterprises to different groups. Majority of those data are from the Micro enterprise and small enterprise, which consists over 70 percent of total data.

Then Martin made the statistical hypothesis test. “ This hypothesis is focused on the relationship between the size of SMEs and the most frequent method of measurement of the customers' value. The hypothesis has been verified by using the binary logistic regression method. " $\mathrm{H0}$ - The application method of measurement of the customers' value according to the long-term relationship does not depend on the field of business." [1]

After the hypothesis statement, Martin applies logistic regression to the dataset to test the hypothesis test. The logistic regression used by Martin is to figure out the relationship among uncontentious dichotomous dependent variables which are YES/NO of measuring customer value on the long-term relationship.

\section{RESULTS OF THE SMES VALUATION OF COSTUMER VALUES AND ANALYSIS}

Based on this result $49.6 \%$ of respondents use the customer's value to figure out the price of individual customers. The reason why many filed businesses consider this one as important part may be due to the size of the small enterprises, it is capable for them to make personalization pricing for their individual customers. Those microenterprise and small enterprises can adjust their price quickly. Based on another essay written by Nichifor, he mentions that small and medium companies tend to become digital and can offer more personalization services, such as advertisement to the consumers. [7]. It may be one of the reasons why those enterprises consider the pricing for the individual customers is the most crucial factor of customer valuation.

Table 2 Use of customer value measurement in SMEs marketing activities in 2015(\% of the number of companies in the field of business) [1]

\begin{tabular}{|l|l|l|l|l|l|l|}
\hline \multirow{2}{*}{ Used for: } & \multicolumn{3}{|l|}{ The field of business } \\
\cline { 2 - 8 } & \multicolumn{2}{|l|}{ Production } & \multicolumn{2}{l|}{ Services } & \multicolumn{2}{l|}{ Retail } \\
\cline { 2 - 8 } & $\%$ & Ranking & $\%$ & Ranking & $\%$ & Ranking \\
\hline $\begin{array}{l}\text { A: a segmentation by customer } \\
\text { value }\end{array}$ & 10.1 & 6. & 15.7 & 5. & 6.5 & 7. \\
\hline B: product value differentiation & 52.9 & 2. & 32.8 & 4. & 24.5 & 4. \\
\hline $\begin{array}{l}\text { C: determination of pricing for } \\
\text { individual customers }\end{array}$ & 55.1 & 1. & 50.1 & 1. & 42.9 & 1. \\
\hline $\begin{array}{l}\text { D: suggestion of distribution channe } \\
\text { for individual customers }\end{array}$ & 29.1 & 4. & 11.2 & 6. & 18.9 & 6. \\
\hline $\begin{array}{l}\text { E: using for individual customer } \\
\text { relationship management }\end{array}$ & 29.1 & 5. & 41.3 & 2. & 19.3 & 5. \\
\hline $\begin{array}{l}\text { F: to maintain customer loyalty } \\
\text { (after-sales communication) }\end{array}$ & 51.4 & 3. & 39.7 & 3. & 33.0 & 2. \\
\hline G: to calculate customer investment & 9.4 & 7. & 9.9 & 7. & 25.0 & 3. \\
\hline
\end{tabular}

Communication with the consumers and product value differentiation is second and third place. Only $14.8 \%$ of the respondents tend to make a segmentation by customer value. Due to most of those companies are small or micro size, there will be no need for those companies to make a segmentation for their customers, since they may have a small costumer group. However, the loyalty for those companies may become very important. Staffs of the SME should be encouraged to build a long-term relationship towards customers lasting relationships that can be seen as a crucial element of differentiation and a means to gain greater credibility[6]. Therefore, it is the reason why over half of the companies believe to maintain customer loyalty as top rank. 
Table 3 The methods used to measure customer value in SMEs in 2015

\begin{tabular}{|l|l|l|l|l|l|}
\hline The method of measurement & \multicolumn{4}{l|}{ Yes } & No \\
\cline { 2 - 7 } & Frequency & $\%$ & Ranking & Frequency & $\%$ \\
\hline A: according to the sales value & 261 & 35.5 & 2. & 475 & 64.5 \\
\hline B: according to the profitability & 229 & 31.1 & 3. & 507 & 68.9 \\
\hline C: according to the business margin & 39 & 5.3 & 5. & 697 & 94.7 \\
\hline $\begin{array}{l}\text { D: according to the long-term } \\
\text { relationships }\end{array}$ & 359 & 48.8 & 1. & 377 & 51.2 \\
\hline $\begin{array}{l}\text { E: according to the market position } \\
\text { (image) }\end{array}$ & 42 & 5.7 & 4. & 694 & 94.3 \\
\hline F: using the ABC method & 17 & 2.3 & 6. & 719 & 97.7 \\
\hline
\end{tabular}

Based on this table " The most respondents measure the customer value according to the long-term relationships (D), 48.8\%. " [1]. The long-term customer loyalty and its high value can help to get loyalty programs that we can find in many fields [5]. Thus, most companies aim for the long-term relationship or improvement of the customer loyalty program. If an enterprise has a wild range of customers, it will be more difficult for those costumers to adjust their benefits and profits. Some small and medium-sized enterprises is able to adjust their valuation due to it is closer to the customers.

Table 4 Measuring customer value in SMEs in 2015 according to the field of business [1]

\begin{tabular}{|c|c|c|c|c|c|c|}
\hline \multirow[t]{3}{*}{ The method of measurement } & \multicolumn{6}{|c|}{ The field of business } \\
\hline & \multicolumn{2}{|c|}{ Production } & \multicolumn{2}{|c|}{ Services } & \multicolumn{2}{|c|}{ Retail } \\
\hline & $\%$ & Ranking & $\%$ & Ranking & $\%$ & Ranking \\
\hline A: according to the sales value & 26.8 & 2. & 34.9 & 2. & $\begin{array}{l}43 . \\
4\end{array}$ & 1. \\
\hline B: according to the profitability & 25.4 & 3. & 31.2 & 3. & $\begin{array}{l}36 . \\
3\end{array}$ & 3. \\
\hline C: according to the business margin & 7.2 & 5. & 2.9 & 5. & 8.5 & 4. \\
\hline $\begin{array}{l}\text { D: according to the long-term } \\
\text { relationships }\end{array}$ & 71.0 & 1. & 42.1 & 1. & $\begin{array}{l}43 . \\
4\end{array}$ & 2. \\
\hline $\begin{array}{l}\text { E: according to the market position } \\
\text { (image) }\end{array}$ & 9.4 & 4. & 6.7 & 4. & 1.4 & 6. \\
\hline F: using the $\mathrm{ABC}$ method & 3.6 & 6. & 2.1 & 6. & 1.9 & 5. \\
\hline
\end{tabular}

Based on this table, it is clear to notice that the companies on the production filed consider the long-term relationships as the most important customer value. The services filed consider the long-term relationship as important as the sales value and profitability. The retail filed has the same weight on both sales value and the long-term relationships for the customer value measurement. Costumers are increasing purchasing online for goods and services and the satisfaction causes customer loyalty. [9]. In production and service firm may all consider the long-term relationship as the most important customer value due to the satisfaction of costumers increases the loyalty and then increase the purchase, which will bring them more profits.

Finally, Martin tests the hypothesis test made early to find out those applications ways to long-term relationships are not dependent on the field of business.

Table 5. The estimation of logistic regression for SMEs size and application of measuring customer value according to the long-term relationships[1]

\begin{tabular}{|c|c|c|c|c|c|c|c|}
\hline & \multirow[t]{2}{*}{ Estimate } & \multirow{2}{*}{$\begin{array}{l}\text { Std. } \\
\text { Error }\end{array}$} & \multirow[t]{2}{*}{ Wald } & \multirow[t]{2}{*}{$\mathrm{df}$} & \multirow[t]{2}{*}{ Sig. } & \multicolumn{2}{|c|}{$95 \%$ Confidence Interval } \\
\hline & & & & & & $\begin{array}{l}\text { Lower } \\
\text { Bound }\end{array}$ & $\begin{array}{l}\text { Upper } \\
\text { Bound }\end{array}$ \\
\hline $\begin{array}{l}\text { Threshold } \\
\text { The long-term } \\
\text { relationships }\end{array}$ &, 924 &, 182 & 25,879 & 1 &, 000 &, 568 & 1,279 \\
\hline $\begin{array}{l}\text { Location } \\
\text { Field of SMEs }\end{array}$ &, 504 & ,099 & 25,946 & 1 &, 000 &, 310 & ,698 \\
\hline
\end{tabular}


According to the table above, it is clear to review that the way of measuring customer value is dependent on the field of business. The statistically significant coefficients occurred because the significant value is less than 0.05 . The alternative hypothesis stated by the author, which is $\mathrm{H} 1$ - the application way of measuring customer value according to the long-term relationships are dependent on the field of business, [1] should be accepted based on this result. Thus, it is varied from different field of business based on the results of authors hypothesis test. Then, some potential question may be that whether some different area filed of business, especially digital businesses measure the consumer value in the same way?

\section{COMPRESSION OF THE SMES'}

VALUATION AND FIND OUT WHICH
PARTS NEEDS MORE EXPLANATION.

Based on Martin' results and conclusion, we realize that the customer long-term relationship is one of the most important customer-value measurements. The long-term relationship, sale value, and customer profitability are the most common methods of measuring customer value for the company. [1] Meanwhile, based on the hypothesis testing result, the approaches of measuring customer value vary depend on the different filed of business. The field of business does determine the measurement of customer value based on the costumer' s loyalty. The main value for those services and production flied business company tend to put the customer loyalty as the first place to consider the customer evaluation. Sales value and the length of the relationship is preferred by the Retail companies.

\section{A CASE STUDY OF BIG ENTERPRISE- WEIBO}

Based on all the analysis, there are no difference between the selection of approaches to measure the costumer value for 10 years. This situation is caused by lack of more effective ways to measure customer value. In this article, there are some insufficiency in consumer value measure method by pointing out that there is some variation between customer value and satisfaction. The CRM is aimed to measure the consumer' s satisfaction and loyalty. SME can build more person connection with customers in order to analyze their behavior and target specific customer groups. The author also points out that SME severs part of CRM.

Martin is trying to focus on the frequency appear in different tables. After the analysis of the sample data set, he made a segmentation of different enterprise and assign those companies to Microenterprise, small and medium. Therefore, it is obvious that those results are mainly useful to some small and medium level enterprises size. How the large enterprise defines consumer values and consider which aspects is the most important filed is still unknown. Large enterprise make adjustment about their pricing services based on the customer valuation result may be different. It is hard for big enterprise make sudden adjustment about product pricing. Meanwhile, there are lack of some costumers' long-term relationship importance for big enterprise. Since those enterprise have many customers, lose small number of customers may not be as important as small or micro enterprise. On the other hand, digital business filed may also have different variation of the customer value. The costumer valuation for those online enterprises may vary differently.

There is a perfect case study made by scholar Huiqin to talk about a very large online digital enterprise, Weibo. Weibo is one of biggest digital application in China which has over 1 billion users. It fulfills the digital business and a large enterprise with different groups of costumers. [2]

In this paper, the author Zhang explains how Weibo makes profits. As a combination of the Facebook and Twitter, Weibo dominates the Chinese marketplace and have some opportunities to build mutually profitable relationships with different companies. According to the data of Weibo form 2009 and 2019 provided by the researcher Jia, Weibo has over 497 million monthly active users and there are lot of diverse services and products provided by Weibo [4]. Therefore, it will be very attractive and powerful to make some advertisement on Weibo for different customers. And there should be different focus on the customer valuation for online big enterprises. In zhang' s research, he connects some new technology with the customer' $\mathrm{s}$ behavior on this social media and made some hypothesis test to test the correlation. Then, Martin makes a survey to acquire data from 400 undergraduate students and make a data cleaning process. The overall database contains 354 effective data and randomly select 40 out of it.

After the data analysis, Martin gets the conclusion that the Weibo' s quality of services is linked with the customer valuation and customer behavior. The better quality provided by Weibo, the higher likelihood to generate customer value cocreation behavior. Meanwhile, Zhang also mentions that "These results show that the higher a customer' $\mathrm{s}$ collectivist orientation, the stronger is the relationship between the service quality provided on a company' s Weibo page and customer value cocreation behavior" [2]. Based on those findings, we can notice that there are some different between SME and big enterprises. SME may be able to focus more on their pricing area. Big enterprises should consider their customer service as priority. On the other hand, connected recent data capture during 2009-2015 and the new online business 
filed, the long-term relationship is still the most important factors for both online business or reality business, small or big enterprises. Therefore, consideration of the long-term relationship of costumers should be a key factor for business.

\section{CONCLUSION}

After the comparison with SMEs and big enterprise valuation towards the customers value, both parties consider the costumers long-term relationship, royalty as an important factor. Even though different companies have different standard to the customer loyalty and different approaches to enhance the customers loyalty, they all considered the customer loyalty as a crucial factor for the costumer valuation.

On the other hand, for the SMEs in the real business field such as production or retail, costumer's valuation provided those enterprises the ability to adjust their pricing rapidly. For the online digital enterprises, the costumer evaluation provided those enterprises more information to improve their costumer services.

\section{ACKNOWLEDGMENT}

I cannot express enough thanks to my professor and teacher for their continued support and encouragement : Prof. Stephen Coggeshall and teaching assistance Jiaqiong Sun. They have taught me some insights for costumer evaluations and truly inspired me for this paper. My completion of this paper could not have been accomplished without the support of them. Finally, I also want to deeply thanks to my parents as well. They encouraged and motivated me for this challenge and always support me.

\section{REFERENCES}

[1] Chromčáková, Adéla, et al. "The Measurement Methods of Customer Value and Its Use in Small and Medium Sized Czech Enterprises." Scientific Papers of the University of Pardubice. Series D, Faculty of Economics \& Administration, vol. 25, no. 43, May 2018, pp. 87-99.

[2] Zhang, Huiqin, et al. "Value Cocreation Behavior of Customers and Companies on the Weibo Social Media Platform." Social Behavior \& Personality: An International Journal, vol. 48, no. 3, Mar. 2020, pp. 1-11. EBSCOhost, doi:10.2224/sbp.8903.

[3] James C. Anderson and James A. Narus. (2014, August 01). Business Marketing: Understand What Customers Value. Retrieved August 13, 2020, from https://hbr.org/1998/11/business-marketing-underst and-what-customers-value

[4] Jia, Lianrui, and Xiaofei Han. "Tracing Weibo (2009-2019): The Commercial Dissolution of
Public Communication and Changing Politics." Internet Histories, vol. 4, no. 3, Sept. 2020, pp. 304-332. EBSCOhost, doi:10.1080/24701475. 2020.1769894 .

[5] Kotler, P., Keller, K. L. (2012). Marketing management. 14. vyd. Praha: Grada Publishing.

[6] Khalifa, Ali Haj, and Mohammed Saad. "The Determinants of Trust in the Customer-Service Provider Relationship: The Case of Tunisian Small and Medium-Sized Enterprises (SMEs)." International Journal of Technology Management \& Sustainable Development, vol. 16, no. 3, Sept. 2017, pp. 295-310. EBSCOhost, doi:10.1386/tmsd. 16.3.295_1.

[7] NICHIFOR, E., and O. M. ȚIEREAN. "Small and Medium Enterprises Go Digital." Bulletin of the Transilvania University of Brasov, Seriels VI: Medical Sciences, vol. 12, no. 2, July 2019, pp. 61-66. EBSCOhost, doi:10.31926/but.es. 2019. 12.61.2.8.

[8] Patterson, L. (2020, March 02). How to Measure Customer Value (And Why It Matters). Retrieved August 13, 2020, from https://talentedlearning.com/how-to-measure-custo mer-value-why-it-matters

[9] Radionova-Girsa, Elina. "The Customer Loyalty Problems: Online Problems.” Proceedings of the Multidisciplinary Academic Conference, Oct. 2017, pp. 28-36. EBSCOhost, search.ebscohost.com/login.aspx .direct $=$ true $\& \mathrm{db}=$ asn $\& A N=125663058 \&$ site $=$ ehost-live. 